\title{
Action potentials in abscisic acid-deficient tomato mutant generated spontaneously and evoked by electrical stimulation
}

\author{
F. C. O. Macedo ${ }^{1} \cdot$ H. Dziubinska ${ }^{2} \cdot$ K. Trebacz ${ }^{2} \cdot$ R. F. Oliveira ${ }^{1} \cdot$ \\ R. A. Moral $^{1}$
}

Received: 7 May 2015/Revised: 28 July 2015/Accepted: 26 August 2015/Published online: 18 September 2015

(C) The Author(s) 2015. This article is published with open access at Springerlink.com

\begin{abstract}
Action potentials generated spontaneously (SAPs) and evoked by electrical stimulation (APs) in tomato plants (Solanum lycopersicum L.) cv. Micro-Tom ABA-deficient mutants (sitiens-MTsit) and its wild type (MTwt) were characterized by continuous monitoring of electrical activity for $66 \mathrm{~h}$ and by application of an electrical stimulation supplied extracellularly. MTsit generated SAPs which spread along the stem, including petioles and roots with an amplitude of $44.6 \pm 4.4 \mathrm{mV}$, half-time $\left(t^{1 / 2}\right)$ of $33.1 \pm 2.9 \mathrm{~s}$ and velocity of $5.4 \pm 1.0 \mathrm{~cm} \mathrm{~min}^{-1}$. Amplitude and velocity were 43 and $108 \%$ higher in MTsit than in MTwt, respectively. The largest number of SAPs was registered in the early morning in both genotypes. MTsit was less responsive to electrical stimuli. The excitation threshold and the refractory period were greater in MTsit than in MTwt. After current application, APs were generated in the MTwt with $21.2 \pm 2.4 \mathrm{mV}$ amplitude and propagated with $5.6 \pm 0.5 \mathrm{~cm} \mathrm{~min}^{-1}$ velocity. Lower intensity stimuli did not trigger APs in these plants. In MTsit APs were measured with amplitude of $26.8 \pm 4.8 \mathrm{mV}$ and propagated with velocity of $8.5 \pm 0.1 \mathrm{~cm} \mathrm{~min}^{-1}$.
\end{abstract}

Keywords ABA - Action potential - Electrical signal . Sitiens $\cdot$ Stress

Communicated by H. Li.

H. Dziubinska

halina.dziubinska@poczta.umcs.lublin.pl

1 Department of Biological Science, University of São Paulo, Piracicaba 13418 900, Brazil

2 Department of Biophysics, Maria Curie-Skłodowska University, Akademicka 19, 20-033 Lublin, Poland

\section{Introduction}

The intracellular and intercellular signaling in plants occurs through signals derived from hydraulic, chemical and electrical sources. Stephen Hales' experiments inaugurated the hydraulic signals research in plants in the early eighteenth century (Hales 1961). Afterwards, many studies involving root to shoot long distance signaling demonstrated the involvement of hydraulic signals in water absorption and growth mechanisms as well as in the control of the stomatal conductance (Hsiao 1973; Malone 1993; Christmann et al. 2007). In the twentieth century, after the discovery of plant hormones (Audus 1959), the scientists turned their attention to these substances such as auxin, gibberellins, abscisic acid, ethylene, cytokinins, brassinosteroids, salicylic acid, and jasmonic acid (Davies 2010). With the advent of molecular biology, the understanding of the mechanisms of cell-cell and organ-organ communication by phytohormones, peptides, nucleotides, fatty acids, reactive oxygen species, and others, has been improved; evidencing chemical signals as having a major role in signaling processes (Mulligan et al. 1997; Apel and Hirt 2014; Kushwah and Laxmi 2014; Sanchita et al. 2014).

On the other hand, the electrical signaling has received less attention from the plant biologists. The first known recording of the electrical signal in plants was registered by John Burdon-Sanderson in 1873, on carnivorous plant Dionaea muscipula leaves (Pickard 1973). The fact that plants are electrically excitable and able to generate and propagate electrical signals is well documented. Two main types of electrical signals are recognized in plants: the action potentials (APs) and the variation potentials (VPs). The AP can be defined as instantaneous change in the electrical potential of the cell membrane. After being 
triggered, the AP propagates with constant speed and amplitude according to the "all-or-nothing" principle (Pyatygin and Opritov 1990). The VP results from variations in the xylem tension, which alter the turgor pressure of the adjacent cells to the vessels eliciting local electrical potential changes. The amplitude and velocity of the VP decreases with the distance from the site of the stimulus (Stanković et al. 1997).

Not only hydraulic and chemical signals, but also electrical signals act on the perception of environmental stimuli and trigger biochemical and physiological changes such as elongation, growth, water transport, displacement of substances in phloem, reduction of turgor pressure, variation of photosynthesis, respiration, and gene expression, mediating the relation between the plant and its external environment (Dziubinska et al. 1989; Stanković and Davies 1996; Huang et al. 2006; Fromm and Lautner 2007; Yan et al. 2009). It becomes increasingly clear that the long distance signaling involves the integration of many signals. Mechanical and chemical stimuli may cause changes in membrane potential which in some specific situations results in generation of an action potential (Krol et al. 2010). Therefore, it is necessary to investigate the possible correlations among different types of signals in order to set an integrated view of signaling mechanisms in the plant as a whole.

Abscisic acid (ABA) regulates numerous growth and developmental process such as embryo and seed development, germination, seedling establishment, vegetative development as well as general growth, and reproduction. However, ABA roles in plant biotic and abiotic stress response, especially in water relations, are considered the most important physiological effects. ABA level increased substantially in dry conditions and several studies have revealed its actions to the stomata closing, root growth and genes expression involved in responses to stress. All these ABA effects have been extensively reviewed (Cutler et al. 2010; Nilson and Assmann 2007; Jiang and Hartung 2008). It has long been known that abscisic acid (ABA) associated with hydraulic signals plays a critical role in root-shoot communication regarding the soil water status (Wilkinson and Davies 2002; Kim 2014). It has also been observed the involvement of action potentials in that mechanism (Fromm and Fei 1998; Wang et al. 2007; Gil et al. 2009). The use of mutants proved to be an important tool for plant signaling studies. Thus, characterizing the generation of action potentials in ABA-deficient plants, it is worthwhile to investigate the relationship between electrical signals and ABA.

In the present study, action potentials generated spontaneously and evoked by electrical stimulation were characterized in the tomato, cv. Micro-Tom, mutant sitiens which has only approximately $8 \%$ of ABA total level of the wild type. The sitiens wilty mutant is deficient in functional enzyme activity - aldehyde oxidase (AO) at the final step in ABA biosynthesis, so sit is impaired in the conversion of ABA-aldehyde to ABA (Taylor et al. 1988). It took a long time for the sitiens gene and its mutant alleles to be identified. Harrison et al. (2011) found a new tomato aldehyde oxidase (TAO) gene by obtaining an accurate map position and then searching for aldehyde oxidase genes in that genomic region, making use of the tomato whole genome shotgun sequence assembly. This novel TAO gene is therefore, named as the sit gene. The reduced ABA content is responsible for the lower growth rate of sitiens compared to wild type. The mutant shows a high transpiration rate and a low hydraulic conductivity of root, which explains its low leaf water potential and turgor. These factors result in reduced leaf expansion, characterizing their smaller size and their wilting appearance in relation to the wild type (Fig. 1) (Nagel et al. 1994). Because of its small size, simple genetics, short life cycle, sitiens and its wild type are convenient models for plant physiological studies.

Here we present an electrophysiological characterization of those plants, concerning excitability, excitation threshold, refractory period, amplitude, speed, duration and direction of propagation of spontaneous action potentials (SAPs) and APs evoked by electric current application.

\section{Materials and methods}

\section{Plant material and growth conditions}

The seeds of tomato (Solanum lycopersicum L.) cv. MicroTom mutant sitiens (MTsit) and wild type (MTwt) have been provided from the Micro-Tom collection of the

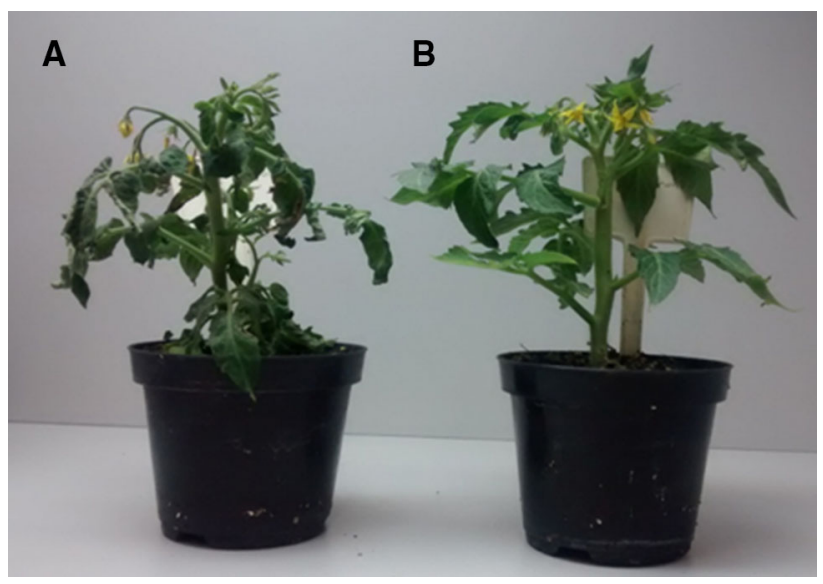

Fig. 1 Tomato plants cv. Micro-Tom 30 days' old grown in greenhouse, under the same environmental conditions. ABA-deficient mutant sitiens (a) and wild type (b) 
Laboratory of Hormonal Control of Plant Development of São Paulo University, Brazil.

The plants grew in a room with no windows, where the temperature was kept at $22-25{ }^{\circ} \mathrm{C}$, humidity of $40-60 \%$, and a photoperiod of $14 \mathrm{~h}$ light (white fluorescent lights of $120 \mu \mathrm{mol} \mathrm{m}{ }^{-2} \mathrm{~s}^{-1}$ PAR at the plant level). Mutant plants were grown in the same room in a covered glass boxes where the humidity was around 70-90\%.

\section{Electrical activity recording}

The experiments were carried out in a room with the same conditions of temperature and humidity as the growth room, but illuminated with a fluorescent light of $15 \mu \mathrm{mol} \mathrm{m} \mathrm{s}^{-1}$ (PAR) at the level of the plant and photoperiod of $15 \mathrm{~h}$ light.

50- to 60-day-old plants were placed in a Faraday cage to ensure electromagnetic isolation. Four measuring electrodes $(0.2 \mathrm{~mm}$ diameter silver wire) inserted along the stem or petiole were used with different arrangements. The reference electrode was inserted into the stem or placed in the ground. The measurements were initiated $3 \mathrm{~h}$ after the insertion of electrodes in the plants: time required for the voltage to be stabilized in all of the electrodes. The input resistance of each channel was $100 \mathrm{M} \Omega$. The electrodes were connected to a data acquisition system with four channels, which was connected to a computer and controlled by the software "RealView".

Spontaneous action potentials (SAPs) were measured by continuous monitoring of electrical activity for $66 \mathrm{~h}$. During this time the laboratory was closed to eliminate any external influence and conditions were kept constant, except for the automatically switching lights off and on.

In order to record action potentials (AP) evoked by electrical stimulation, an electric current was supplied extracellularly through $\mathrm{Ag} / \mathrm{AgCl}$ surface electrodes. Different voltages were used to determine the excitation threshold.

\section{Statistical analyses}

All analyses were carried out using statistical software R (R Core Team 2014).

A linear mixed model was fit to SAP amplitude, duration $\left(t^{1 / 2}\right)$ and velocity with a random intercept per plant and genotype fixed effect. Significance of the genotype effect was assessed using F tests (Bolker et al. 2009).

Analysis of variance models were fit to electric variables (amplitude, duration and velocity) with the fixed effect of genotype in the linear predictor.

Goodness-of-fit was assessed using half-normal plots with stimulation envelopes (Demétrio et al. 2014).

\section{Results}

\section{Spontaneous action potentials (SAPs)}

Spontaneous action potentials (SAPs) refer to the action potentials generated in the absence of any intentional external stimulus. Their appearance was first described in sunflower by Zawadzki et al. (1995). The results presented here refer to continuous measurements of the electrical activity of ten plants having both genotypes, performed over a period of $66 \mathrm{~h}$ (day/night). SAPs were recorded in $50 \%$ of mutant plants while in wild type this number was $70 \%$. However, the total number of SAPs was equal in both genotypes (Table 1).

According to Krol et al. (2010), excitability means the ability to generate and transmit APs. The cells where the membrane potential varies, but AP does not occur, are not considered excitable. Thus, we considered excitable plants that generated characteristic action potentials, spontaneously or in response to electrical stimulation.

SAPs generated in MTsit and MTwt differ statistically concerning the half-time $\left(t^{1 / 2}\right)$ which was $187 \%$ higher in MTwt compared to MTsit. A marginal statistical difference can be considered regarding the amplitude and propagation velocity. The amplitude, and propagation velocity (measured between two electrodes located consecutively in the plant) were 43 and $108 \%$ higher in mutant plants than in wild type plants, respectively (Table 2).

SAPs recorded in MTwt (Fig. 2b) and in MTsit (Fig. 3a, b) propagated through the stem and petioles in different directions.

The direction of propagation of SAP is difficult to be defined because it is impossible to know exactly where the signal began. It is possible to make an inference observing the electrode where the signal was first registered. However, inferences must be made carefully. In Fig. 2b, a recording of spontaneous action potentials in wild type plant can be observed. First, the signal with reversed polarity was registered simultaneously by all four electrodes indicating that the reference electrode detected the AP in the roots through the soil. Then, the signal was recorded sequentially by the four electrodes located along the stem which indicates AP spreading from the roots to the apex. In Fig. 3a and b, the SAP spread over the stem and petioles. In both presented recordings it originated in an apical part of the plant which was concluded on the basis of the sequence of SAP appearance (El.1, El.2, El.3, and El.4). In Fig. 3a, it is, also, possible to see how hard it is to know the beginning of the SAP. The signal is recorded almost simultaneously at electrodes located in different parts of the plant (El 1 and $\mathrm{El} 2$, inserted in the petiole and stem, respectively, Fig. 3a). Note that in the experiment 
Table 1 Number of examined plants, number of plants that generated SAPs, total number of SAPs and excitability recorded during $66 \mathrm{~h}$ of continuous measurements of electrical activity in MTwt and MTsit

\begin{tabular}{lllll}
\hline Genotypes & No. of plants & No. of plants/SAP & Total no. of SAPs & Excitability (\%) \\
\hline MTwt & 10 & 7 & 19 & 70 \\
MTsit & 10 & 5 & 19 & 50 \\
\hline
\end{tabular}

Table 2 Amplitude, half-time $\left(t^{1 / 2}\right)$ of the SAP measured at half of its height (amplitude), propagation velocity of SAP generated in MTwt and MTsit during $66 \mathrm{~h}$ of continuous registration

\begin{tabular}{llll}
\hline Genotypes & Amplitude $(\mathrm{mV})$ & $t^{1 / 2}(\mathrm{~s})$ & ${\text { Propagation velocity }\left(\mathrm{cm} \text { min }^{-1}\right)}^{\text {a }}$ \\
\hline MT $w t$ & $31.17( \pm 1.91)^{\mathrm{b}}$ & $94.78( \pm 12.83)^{\mathrm{a}}$ & $2.59( \pm 0.61)^{\mathrm{a}}$ \\
MTsit & $44.55( \pm 4.40)^{\mathrm{a}}$ & $33.07( \pm 2.89)^{\mathrm{b}}$ & $5.39( \pm 1.01)^{\mathrm{a}}$ \\
$p$ & $0.06^{* *}$ & $0.02^{*}$ & $0.07^{* *}$ \\
\hline
\end{tabular}

* Significant statistical difference. ** Marginally significant statistical difference $(p<0.05) ; n=10$; mean $( \pm \mathrm{SD})$

Fig. 2 Characteristic traces of SAP generated in tomato MTwt. Diagram of the electrode arrangement (a). Signal recorded at all electrodes (b). Distances between the electrodes El 1 and El 2, El 2 and El 3, El 3 and El 4 were: $1.0,1.0$ and $1.0 \mathrm{~cm}$, respectively
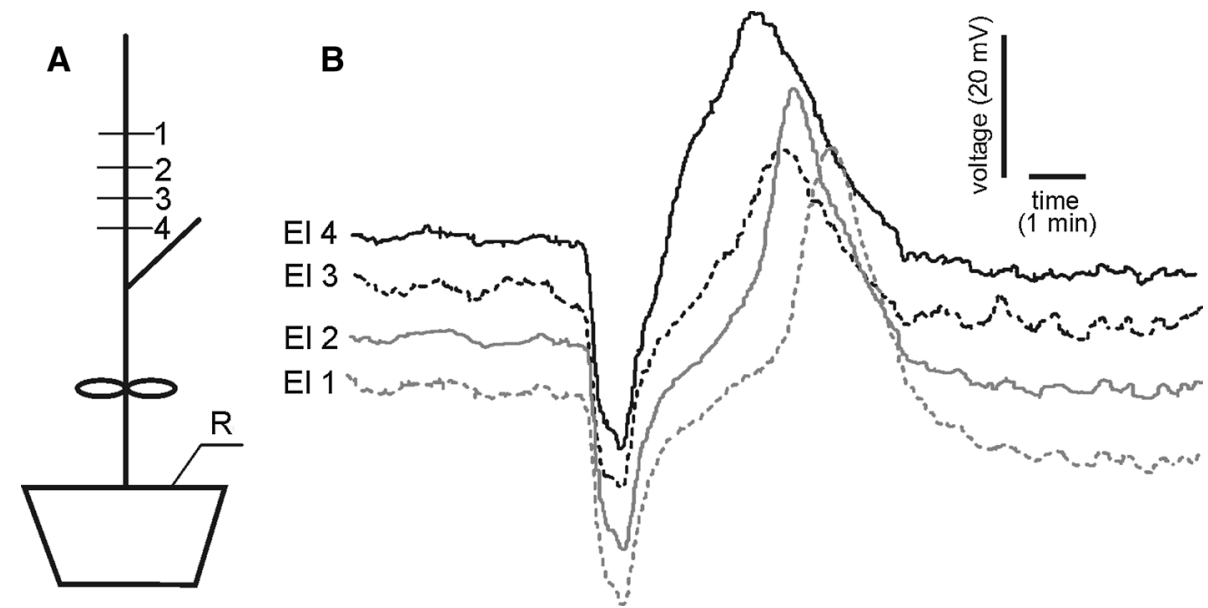

Fig. 3 Characteristic traces of SAP generated in tomato MTsit. SAP registered with the reference electrode placed in the soil (a) or inserted into the stem apex (b). El 1 and El 2, El 2 and El 3, El 3 and El 4 were: 1.0, $1.5,1.2 \mathrm{~cm}$ (a) and $0.8,1.0$, $0.8 \mathrm{~cm}(\mathbf{b})$, respectively

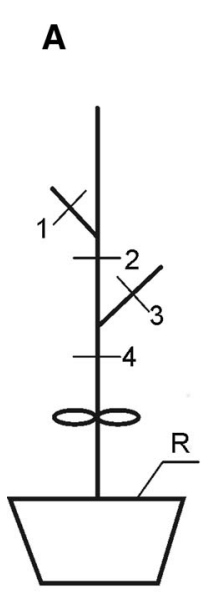

B

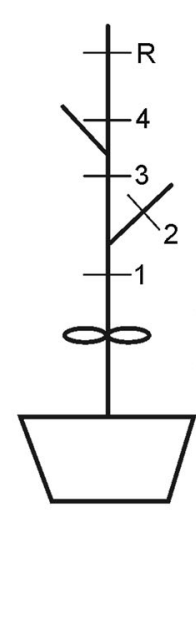

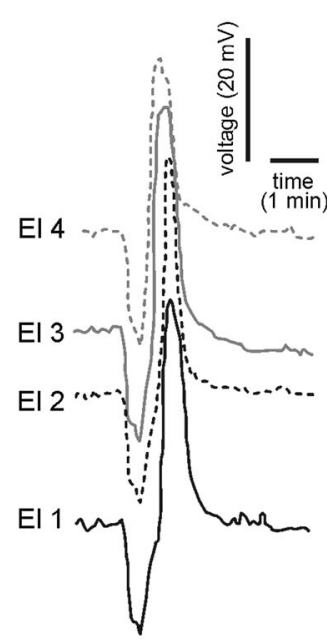


shown in Fig. 3b the reference electrode was inserted in the apical part of the stem.

In Fig. 4 frequency of SAPs generation during a 24-h period is presented. The highest number of SAPs occurred in early morning, for both genotypes, whereas in MTsit the highest number of SAPs occurred between 04 and 08 a.m. In case of wild type plants, the highest numbers of the SAPs were registered from 06 to 08 a.m.

\section{Action potentials evoked by electrical stimulation}

The minimum electrical stimulus required to trigger action potentials in MTwt was 8 V/4 s. Stimuli of lower intensities were tested but did not lead to generation of action potentials. Electrical stimulation of $4 \mathrm{~V} / 5 \mathrm{~s}$, for example, caused a local depolarization which did not spread. Regarding MTsit, only the application of an electrical current of $9 \mathrm{~V} / 9 \mathrm{~s}$ triggered action potentials, indicating that the threshold of excitation of the mutant was higher than in the wild type. Furthermore, the excitability of mutant plants was only $20 \%$ compared to $70 \%$ in MTwt and the refractory period was longer in MTsit $-5 \mathrm{~h}$ than in MTwt -4 h (Table 3).

Stimuli of higher or equal intensity at intervals of 1, 2, 3 and $4 \mathrm{~h}$ were tested, but no change in the membrane potential or only slight depolarizations were observed.

Action potentials evoked by electrical stimulation exhibited higher amplitude and velocity of propagation in MTsit than MTwt (Table 4). An important question that arises from our results is why the APs in mutant plants propagate with higher amplitude and velocity than in wild type plants.

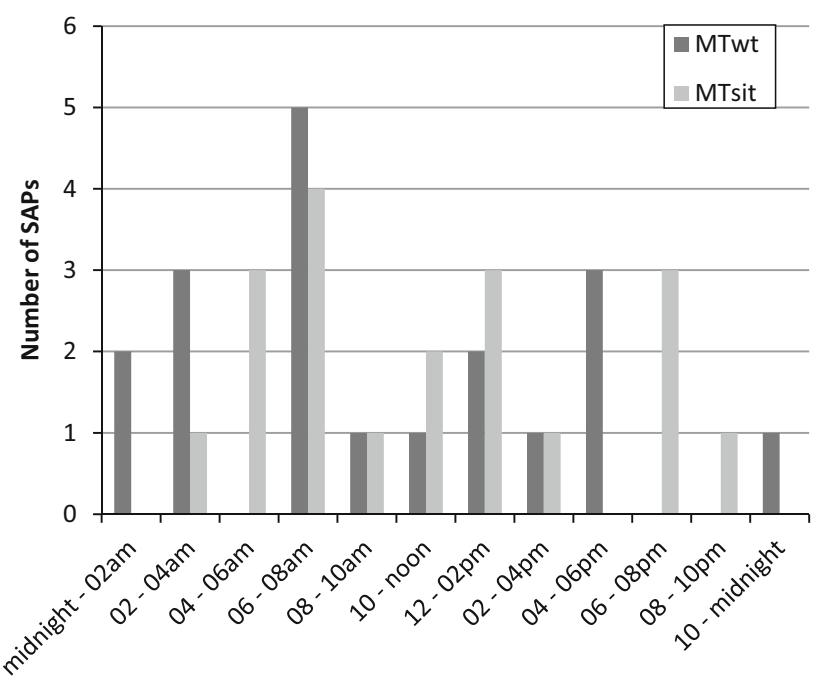

Fig. 4 Frequency of SAPs generation in MTsit and MTwt in a 24-h period
APs evoked by electrical stimuli show uniform shape and propagated basipetally and acropetally through the stem and petioles, in both wild type and mutant plants (Fig. 5a, b). However, the APs seem not to reach the leaves or hypocotyls region (data not shown). In the mutant plants, a slight downward peak, after an upward peak was recorded, this indicates that the AP has reached the roots. Stimulation was given at the apex of the stem and the reference electrode was in the ground (Fig. 5b).

In Fig. 6, a diagram is shown which demonstrates a route of propagation of action potential evoked by electrical stimulation. After electrical stimulation (vertical dashed line) the signal was first recorded at electrode 3 (vertical line a), then it was recorded almost simultaneously in the electrodes 2 and 4 (vertical line b), and finally measured in electrode 1 (vertical line c) (Fig. 6b).

The recordings shown in Fig. 6 indicate a possible route of transmission of AP in this specific situation. The AP originated near the cathode and propagated by the stem basipetally. Upon reaching the connection between the stem and petiole, the signal then bifurcated, following the architecture of conducting vessels. The signal first reached electrode 3 , which was located closer to the stimulus, then electrodes 2 (in the petiole) and 4 (stem) simultaneously, since the distance between these electrodes and the cathode was equal. The electrode 1 was inserted the longest distances from the stimulus and, therefore, was the last to record the signal.

\section{Discussion}

The causes of the SAPs generation are unknown, but their frequency or rhythm show some clues about their physiological significance. The highest number of action potentials generated spontaneously in the early morning can be related to the circadian cycle of the plants, as a photoperiodic response. The accumulation of SAPs at a specific time during a daily cycle of light/dark was also reported by Wagner et al. (2006) who observed a relationship between the generation of APs and the induction of flowering and vegetative growth. The authors concluded that hydraulic changes at the shoot lead to early flowering stage which are mediated by a specific hydro-electrochemical communication among leaves, shoot apex and root system. These experiments have been established to disturb the photoperiod, inducing the flowering by specific 'timing' of electrical stimulation via surface electrodes (Wagner et al. 2006).

The environmental variation should also be considered when observing the generation of SAPs. In the growth room the light was turned on at 6 a.m., thus the highest number of SAPs, at this time, could mean a photoperiodic 
Table 3 Number of tested plants, stimulus intensity, number of plants that generated APs, total number of APs, excitability and refractory period measured after electrical stimulation in MTwt and MTsit

\begin{tabular}{|c|c|c|c|c|c|c|}
\hline Genotypes & No. of plants & Stimulus intensity/duration & No. of plants/AP & Total no. of APs & Excitability $(\%)$ & Refractory period $(\mathrm{h})$ \\
\hline MTwt & 10 & $8 \mathrm{~V} / 4 \mathrm{~s}$ & 8 & 11 & 70 & 4 \\
\hline MTsit & 10 & $9 \mathrm{~V} / 9 \mathrm{~s}$ & 2 & 5 & 20 & 5 \\
\hline
\end{tabular}

Table 4 Amplitude, half-time $\left(t^{1 / 2}\right)$ of the AP measured at half of its amplitude, and velocity of propagation of AP evoked by electrical stimulation in tomato MTwt and MTsit

\begin{tabular}{llll}
\hline Genotypes & Amplitude $(\mathrm{mV})$ & $t^{1 / 2}(\mathrm{~s})$ & Velocity $^{\left(\mathrm{cm} \text { min }^{-1}\right)}$ \\
\hline MTwt & $21.17( \pm 2.43)^{\mathrm{a}}$ & $19.07( \pm 1.93)^{\mathrm{a}}$ & $5.57( \pm 0.51)^{\mathrm{b}}$ \\
MTsit & $26.77( \pm 4.77)^{\mathrm{a}}$ & $19.06( \pm 1.16)^{\mathrm{a}}$ & $8.52( \pm 0.12)^{\mathrm{a}}$ \\
$p$ & 0.27 & 0.99 & $0.01^{*}$ \\
\hline
\end{tabular}

* Significant statistical difference at $5 \%$ probability level. $n=10$; mean $( \pm \mathrm{SD})$

Fig. 5 Diagram of the electrode arrangement and characteristic traces of action potentials evoked by electrical stimulation in tomato, MTwt (a) and MTsit (b). Distances between the cathode (-) and electrodes El 1, El 2, El 3, El 4 were: 0.7, 1.7, $3.6,4.6 \mathrm{~cm}$ (a) and 2.5, 1.5, 0.5, $1.3 \mathrm{~cm}(\mathbf{b})$, respectively

Fig. 6 Possible route of transmission of the action potential in tomato, MTsit, indicated by the grey arrow (a). Particular action potential measured after electrical stimulation. Vertical lines show the time in which the events occur: an arrow time of the stimulus application, $a-c$ time in which the signal is recorded on each electrode (b). Distances between the cathode $(-)$ and electrodes El 1, El 2, El 3, El 4 were: $2.5,1.3,0.5,1.3 \mathrm{~cm}$, respectively
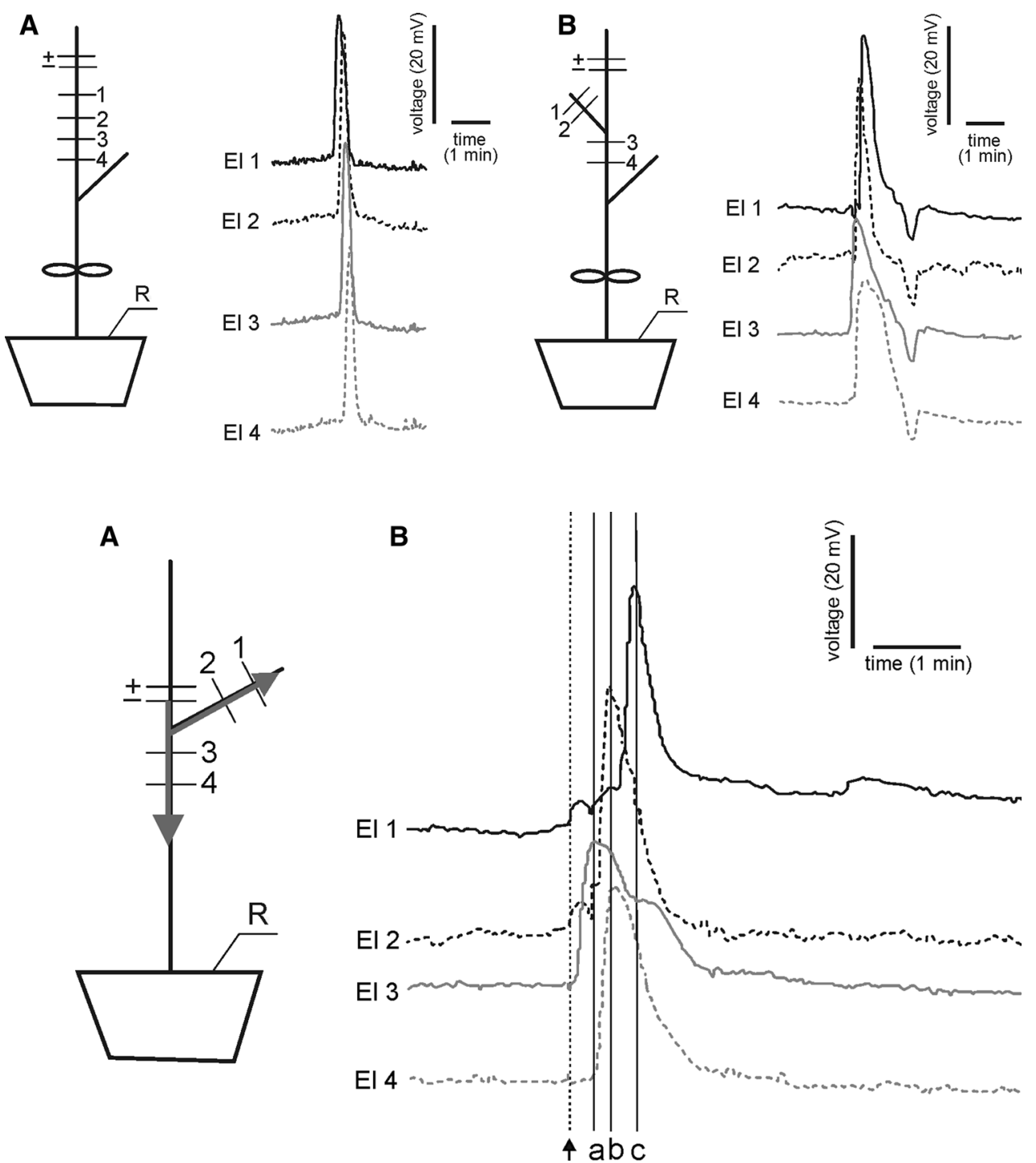
"remembered" response (Goodrich and Tweedie 2002; Bruce et al. 2007; Thellier and Lüttge 2013). In the case of mutant plants, another important factor to be considered is the humidity. ABA-deficient plants are extremely sensitive to water deficit, and the water vapour pressure deficit may be more important than the lack of water in the soil, because the evaporative demand will be higher. Continuous measurements of the electrical activity of the plants over a period of 5 days in which the plants were gradually exposed to water deficit, showed that the mutant plants exhibit electrical responses which increased in time, i.e., when the stress became more severe, more APs were generated, compared to the wild type (data not shown).

SAPs are generated when the membrane potential exceeds the threshold of excitation. In turn, the excitation threshold is achieved when appropriate number of ion channels is activated by a particular stimulus and triggers an AP that propagates with constant amplitude and velocity, i.e., according to the "all-or-nothing" principle. Stimuli of low intensity can cause variations in membrane potential of the cell but do not trigger an AP (Krol et al. 2010). The excitation threshold, as well as the excitability, may vary among species, organs, tissues or cells, since it depends on the activity of ion channels, their phosphorylation/dephosphorylation status and, therefore, the metabolic conditions of each level of organization (Krol et al. 2010). Ion channel activity and/or the number of active ion channels are subjected to circadian control (Stolarz et al. 2010) which may explain diurnal variation in SAP generation. The mutant plants were in a naturally unfavourable conditions and the generation and propagation of APs are energy-costly processes, thus the plants seem to use them only when the damage caused by stress is really severe, 'not compensating'.

The refractory period is the minimum time required so that the resting potential is re-established after the propagation of a signal (Trebacz et al. 1997). It is also necessary time to restore the ion homeostasis in excitable cells. MTsit plants required longer refractory periods than the MTwt plants. Considering plant excitability, we must take into account the metabolic condition (energy) of these plants and not only the content of ABA itself.

The propagation velocity of SAPs was higher in MTsit than in MTwt. The characteristics that defines the APs dependence on the activity of ion channels in cell membranes (Gradmann 1976; Trebacz et al. 1994; Opritov et al. 2002), thus a detailed study of ion activity in these plants, may help to elucidate the results presented here.

According to Herde et al. (1999) the presence of a minimum amount of $\mathrm{ABA}$ is essential for the generation of electrical signals, especially APs in tomato. In their studies with mutant sitiens Herde et al. (1999) did not record APs after electrical stimulation. Only after damaging stimuli such as burning or cutting. In the present study APs evoked by electrical stimulation in MTsit were recorded, but in fact the plants were less responsive to this type of stimulus.

The routes of propagation of AP in plants have been extensively studied and evidence points to the phloem tissue as the propagation pathway for long distances (Fromm and Bauer 1994; Mancuso 1999; Dziubinska et al. 2001). Thus, the architecture of the vascular system determines how far the AP spreads (Krol et al. 2010). In some areas, such as the base of the stalk in Biophytum sensitivum (Sibaoka 1973), or the leaves of Helianthus annuus (Dziubinska et al. 2001), for instance, the AP does not propagate. But this feature also depends on the species in question. In Helianthus we often observed AP propagation to the roots which may have important physiological impact connected to phloem unloading (Fromm and Eschrich 1988). No differences were observed in propagation route between sitiens and wild type plants. This can be explained by the fact that there is no anatomical differences in the vascular system of these plants, although the stem and petiole diameter of sitiens is thinner, due the lower turgor, characteristic of mutant plants (Neill and Horgan 1985; Nagel et al. 1994).

\section{Conclusions}

\section{Spontaneous action potentials}

- The largest number of SAPs occurs in the early morning.

- MTsit generate SAPs that propagate with amplitude and speed 43 and $108 \%$ higher than in MTwt, respectively.

- SAPs propagate through the stem, including petioles and roots.

\section{The plant response to electrical stimulus}

- MTsit are less responsive to electrical stimuli: the excitation threshold and the refractory period are higher than MTwt.

- After stimulation of $8 \mathrm{~V} / 4 \mathrm{~s}$ an AP is generated in the MTwt which propagates with amplitude of $21.2 \pm 2.4 \mathrm{mV}$ and speed of $5.6 \pm 0.5 \mathrm{~cm} \mathrm{~min}^{-1}$. Stimuli of lower intensity did not trigger AP in these plants.

- In MTsit APs were measured after stimulation of $9 \mathrm{~V} /$ $9 \mathrm{~s}$ that spread with amplitude of $26.8 \pm 4.8 \mathrm{mV}$ and velocity of $8.5 \pm 0.1 \mathrm{~cm} \mathrm{~min}^{-1}$.

- APs generated by electrical stimulation propagate acropetally and basipetally along the stem, including petioles. 
Author contribution statement F. C. O. Macedo performed most of the experiments and wrote the first draft of the manuscript. H. Dziubinska planned, interpreted and performed part of the experiments. K. Trebacz interpreted the results and prepared the final version of the text. R. F. Oliveira planned part of the experiments. R. A. Moral performed the statistics.

Acknowledgments We thank Professor Lázaro Eustáquio Pereira Peres of São Paulo University, responsible for the collection of mutant tomatoes, Micro-tom, by providing us seeds used in this work. We also thank Professor Clarice Garcia Borges Demétrio of São Paulo University for reviewing the statistical analysis.

Open Access This article is distributed under the terms of the Creative Commons Attribution 4.0 International License (http://crea tivecommons.org/licenses/by/4.0/), which permits unrestricted use, distribution, and reproduction in any medium, provided you give appropriate credit to the original author(s) and the source, provide a link to the Creative Commons license, and indicate if changes were made.

\section{References}

Apel K, Hirt H (2014) Reactive oxygen species: metabolism, oxidative stress, and signal transduction. Annu Rev Plant Biol 55:373-399

Audus LJ (1959) Plant growth substances. Leonard Hill Books, London

Bolker BM, Brooks ME, Clark CJ, Geange SW, Poulsen JR, Stevens MHH, White JSS (2009) Generalized linear mixed models: a practical guide for ecology and evolution. Trends Ecol Evol 24:127-135

Bruce TJA, Matthes MC, Napier JA, Pickett JA (2007) Stressful "memories" of plants: evidence and possible mechanisms. Plant Sci 173:603-608

Christmann A, Weiler EW, Steudle E, Grill E (2007) A hydraulic signal in root-to-shoot signalling of water shortage. Plant J 53:167-174

Cutler AR, Rodriguez PL, Finkelstein RR, Abrams R (2010) Abscisic acid: emergence of a core signaling network. Annu Rev Plant Biol 61:651-679

Davies PJ (2010) The plant hormones: their nature, occurrence and functions. In: Davies PJ (ed) Plant hormones: biosynthesis, signal transduction, action. Springer, Ithaca, pp 1-15

Demétrio BCG, Hinde J, Moral RA (2014) Models for overdispersed data in entomology. Ecological modelling applied to entomology. Springer International Publishing, Switzerland, pp 219-259

Dziubinska H, Trebacz K, Zawadzki T (1989) The effect of excitation on the rate of respiration in the liverwort Conocephalum conicum. Physiol Plant 75:417-423

Dziubinska H, Trebacz K, Zawadzki T (2001) Transmission route for action potentials and variation potentials in Helianthus annuиs L. J Plant Physiol 158:1167-1172

Fromm J, Bauer T (1994) Action potentials in maize sieve tubes change phloem translocation. J Exp Bot 45:463-469

Fromm J, Eschrich W (1988) Transport process in stimulated and non-stimulated leaves of Mimosa pudica. I. The movement of ${ }^{14} \mathrm{C}$-labelled photoassimilates. Trees 2:7-17

Fromm J, Fei H (1998) Electrical signaling and gas exchange in maize plants of drying soil. Plant Sci 132:203-213

Fromm J, Lautner S (2007) Electrical signals and their physiological significance in plants. Plant Cell Environ 30:249-257
Gil PM, Gurovich L, Schaffer B, García N, Iturriaga R (2009) Electrical signaling, stomatal conductance, $\mathrm{ABA}$ and ethylene content in avocado trees in response to root hypoxia. Plant Signal Behav 4:100-108

Goodrich J, Tweedie S (2002) Remembrance of things past: chromatin remodelling in plant development. Annu Rev Cell Dev Biol 18:707-746

Gradmann D (1976) "Metabolic" action potentials in Acetabularia. J Membr Biol 29:23-45

Hales S (1961) Vegetable staticks. Reprinted from the 1727 edition. Macdonald, London

Harrison E, Burbidge A, Okyere JP, Thompson AJ, Taylor IB (2011) Identification of the tomato ABA-deficient mutant sitiens as a member of the ABA-aldehyde oxidase gene family using genetic and genomic analysis. Plant Growth Regul 64:301-309

Herde O, Cortés HP, Wasternack C, Willmitzer L, Fisahn J (1999) Electrical signaling and Pin2 gene expression on different abiotic stimuli depend on a distinct threshold level of endogenous abscisic acid in several abscisic acid-deficient tomato mutants. Plant Physiol 119:213-218

Hsiao TH (1973) Plant responses to water stress. Annu Rev Plant Physiol 24:519-570

Huang L, Wang ZY, Xu ZL et al (2006) Design of multi-channel monitoring system for electrical signals in plants. Mod Sci Instrum 4:45-47

Jiang F, Hartung W (2008) Long-distance signalling of abscisic acid (ABA): the factors regulating the intensity of the ABA signal. J Exp Bot 59:37-43

Kim TH (2014) Mechanism of ABA signal transduction: agricultural highlights for improving drought tolerance. J Plant Biol. 57:1-8

Krol E, Dziubinska H, Trebacz K (2010) What do plants need action potentials for? In: DuBois ML (ed) action potential. Nova Science Publishers Inc, Stanford, pp 1-28

Kushwah S, Laxmi A (2014) The interaction between glucose and cytokinin in signal transduction pathway in Arabidopsis thaliana. Plant Cell Environ 37:235-253

Malone M (1993) Hydraulic signals. Philos Trans R Soc Lond [Biol] 341:33-39

Mancuso S (1999) Hydraulic and electrical transmission of wound induced signals in Vitis vinifera. Aust J Plant Physiol 26:55-61

Mulligan RM, Chory J, Ecker JR (1997) Signaling in plants. Proc Natl Acad Sci USA 94:2793-2795

Nagel OW, Konings H, Lambers H (1994) Growth rate, plant development and water relations of the ABA-deficient tomato mutant sitiens. Physiol Plant 92:102-108

Neill SJ, Horgan R (1985) Abscisic acid production and water relations in wilty tomato mutants subjected to water deficiency. J Exp Bot 36:1222-1231

Nilson SE, Assmann SM (2007) The control of transpiration. Insights from Arabidospis. Plant Physiol 143:19-27

Opritov VA, Pyatygin SS, Vodeneev VA (2002) Direct coupling of action potential generation in cells of a higher plant (Cucurbita pepo) with the operation of an electrogenic pump. Russ J Plant Physiol 49:142-147

Pickard B (1973) Action potentials in higher plants. Bot Rev 39:172-201

Pyatygin SS, Opritov VA (1990) Effect of temperature on action potential generating in higer plant excitable cells. Biofizika 35:444-449

R Core Team (2014). R: A language and environment for statistical computing. R Foundation for Statistical Computing, Vienna, Austria. http://www.R-project.org/. Accessed 21 Oct 2014

Sanchita, Dhawan SS, Sharma A (2014) Analysis of differentially expressed genes in abiotic stress response and their role in signal transduction pathways. Protoplasma 251:81-91 
Sibaoka S (1973) Transmission of action potentials in Biophytum. Bot Mag Tokyo 86:51-62

Stanković B, Davies E (1996) Both action potentials and variation potentials induce proteinase inhibitor gene expression in tomato. FEBS Lett 390:275-279

Stanković B, Zawadzki T, Davies E (1997) Characterization of the variation potential in sunflower. Plant Physiol 115:1083-1088

Stolarz M, Krol E, Dziubinska H, Kurenda A (2010) Glutamate induces series of action potentials and a decrease in circumnutation rate in Helianthus annuus. Physiol Plant 138:329-338

Taylor IB, Linforth RST, Al-Naieb RJ, Bowman WR, Marples BA (1988) The wilty tomato mutants flacca and sitiens are impaired in the oxidation of ABA-aldehyde to ABA. Plant Cell Environ 11:739-745

Thellier M, Lüttge U (2013) Plant memory: a tentative model. Plant Biol 15:1-12

Trebacz K, Simonis W, Schönknecht G (1994) Cytoplasmic $\mathrm{Ca}^{2+}$, $\mathrm{K}^{+}, \mathrm{CI}^{-}$, and $\mathrm{NO}^{3-}$ activities in the liverwort Conocephalum conicum $\mathrm{L}$. at rest and during action potentials. Plant Physiol 106:1073-1084

Trebacz K, Stolarz M, Dziubinska H, Zawadzki T (1997) Electrical control of plant development. In: Greppin H, Penel C, Simon P (eds) Travelling shot on plant development. University of Geneva, Geneva, pp 165-181

Wagner E, Lehner L, Normann J, Veit J, Albrechtová J (2006) Hydroelectrochemical integration of the higher plant-basis for electrogenic flower induction. In: Baluska F, Mancuso S, Volkmann D (eds) Communication in plants. Springer-Verlag, Berlin, pp 369-387

Wang C, Huang L, Wang Z, Qiao X (2007) Monitoring and analysis the electrical signals in water-stressed plants. N Z J Agric Res 50:823-829

Wilkinson S, Davies WJ (2002) ABA-based chemical signalling: the co-ordination of responses to stress in plants. Plant Cell Environ 25:195-210

Yan X, Wang Z, Huang L et al (2009) Research progress on electrical signals in higher plants. Prog Nat Sci 19:531-541

Zawadzki T, Dziubinska H, Davies E (1995) Characteristics of action potentials generated spontaneously in Helianthus annuus. Physiol Plant 93:291-297 